\title{
Validation of a Screening Model for Referrals to Support Students with Hidden Disabilities in Higher Education
}

\section{Alma Dizdarević1, Vesna Bratovčić1, Senad Mehmedinović1, Amila Mujezinović1, Selma Porobić ${ }^{2}$, Bahira Demirović ${ }^{3}$}

${ }^{1}$ Faculty of Education and Rehabilitation, University of Tuzla, Tuzla, Bosnia and Herzegovina

${ }^{2}$ Faculty of Philosophy, University of Tuzla, Tuzla, Bosnia and Herzegovina

${ }^{3}$ Center for Special Education "Mejedenica", Sarajevo, Bosnia and Herzegovina

Email: alma.dizdarevic@untz.ba

How to cite this paper: Dizdarević, A., Bratovčić, V., Mehmedinović, S., Mujezinović, A., Porobić, S. and Demirović, B. (2018) Validation of a Screening Model for Referrals to Support Students with Hidden Disabilities in Higher Education. Open Journal of Social Sciences, 6, 71-79.

https://doi.org/10.4236/jss.2018.62007

Received: January 12, 2018

Accepted: February 9, 2018

Published: February 12, 2018

Copyright $\odot 2018$ by authors and Scientific Research Publishing Inc. This work is licensed under the Creative Commons Attribution International License (CC BY 4.0)

http://creativecommons.org/licenses/by/4.0/

(c) (i) Open Access

\begin{abstract}
This study describes validation of a screening model for Referrals to Support with Hidden Disabilities in Higher Education. A screening model describes the screening procedures implemented by HEIs in all 8 public universities in Bosnia and Herzegovina. In the study, 5073 bachelor students were participated. There were $1371(27 \%)$ male and 3702 (73\%) female participants. In this research, the questionnaire for students in higher education was used. In order to validate the screening model, a multivariate method of exploratory factor analysis was applied. The intercorrelation of manifest variables was calculated, and on the basis of the obtained coefficients, the variables were selected for further analysis. The variables were subjected by calculating the coefficient of the inner consistency of the Cronbach alpha, and an estimate of the reliability of the variables was made by calculating the interstellar statistics. On the basis of the obtained results of factor analysis, a set of 28 manifest variables have been reduced to 15 variables that have satisfactory reliability and internal agreement, and it is justifiable to use them as a screening model. Findings support the requirement for a reliable and valid standardized assessment procedure for HEIs, which would provide equitable access to an initial diagnosis.
\end{abstract}

\section{Keywords}

Screening Model, Hidden Disabilities, Higher Education 


\section{Introduction}

With the transition to the higher education system of work, where knowledge and skills are constantly evaluated and significantly different from the previous mode of education, many students with disabilities begin a period of customization and search for special adjustments that are in line with their unique needs. Students with "hidden disabilities" comprise the majority of disability conditions [1]. Previous researches indicate increasing number of students with disabilities in the university sector [2] who are often categorized as outsiders [3].

These students face different learning constraints and develop different strategies and mechanisms for coping with difficulties [4], often struggle with low self-esteem and psychological problems [5], and have a bad image of themselves and a higher level of ascension [6], a higher level of loneliness [7], and a lower level of hope in education than students without difficulty [8]. Research indicates that early screening difficulties at the beginning of the study have long-term positive impacts on learning, confidence, and future academic success [9] and long-term perspective of employability.

Discovering hidden disabilities, such as epilepsy, specific learning disabilities, psychiatric disorders, ADHD, ASD, chronic illnesses and the like, is a major burden for students. The main reason for hiding disability is anxiety related to dealing with labeling, stereotypes and stigmatization by teachers, faculty staff, and colleagues. However, students with invisible disabilities are constantly in the dilemma of discovering disability, when to discover it, to whom and how much. In the same position, students that are also minorities, also face additional discrimination regarding their status [10].

In the context of higher education in Bosnia and Herzegovina, all students with disabilities must self-identify their own difficulties and require reasonable adjustments at their universities through the Centers for Support for Students with Special Needs. For students with visible difficulties, there is a University Guide for students with special needs [11], which defines sensory and physical disability and provides opportunities for adjustments, since their difficulties are noticeable and visible immediately after entering the higher education system. However, with invisible difficulties, there are no clear differences between students with disabilities and those without disabilities, considering that their functional deficits are not obvious. Identification of these functional deficits and needs for adjustments require a more thorough process than the existing guidance recommendations can provide [12].

Given that an increasing number of students with invisible difficulties are already in higher education, their difficulties are not identified and that they are at a high risk of leaving the education system as early as the first year of study or studying much longer. These students are unrecognized by the academic staff, so there is need for developing a screening model of early identification and validation of the instrument which was demonstrated. The aim of this paper is to validate the screening model to refer students with invisible difficulties to further assessment and obtain professional support. 


\section{Methods}

\subsection{Participants}

In the study, 5073 bachelor students participated in higher education from all public universities in Bosnia and Herzegovina. There were 1371 (27\%) male and 3702 (73\%) female participants. Most respondents were enrolled in the first year of study 1647 (32.5\%), then in the second year 1504 (29.6\%) and in the third year of study 1238 (24.4\%) respondents. A somewhat smaller number of respondents was recorded on the fourth 597 (11.8\%) and the fifth year of study 87 (1.7\%). Data were collected from 2013 to 2016.

\subsection{Measures}

In this research, the questionnaire for students in higher education was used [13], which was proposed by authors Dizdarević, Duranović and Bijedić. The test was filled out by the participants themselves, and it required approximately 15 minutes to be completed. The Questionnaire for students in higher education consists of two parts. The first part of the Questionnaire consisted of 6 questions related to general information (university and faculty name, sex, year of study, and duration of study). The second part consisted of 28 statements that determined the existence of certain difficulties during study, with answers according to the Likert type scale $(1-5)$.

\subsection{Processing Methods}

In order to verify the validation of the proposed screening model, a multivariate method of exploratory factor analysis was applied. The intercorrelation of manifest variables was calculated, and on the basis of the obtained coefficients, the variables were selected for further analysis.

The variables were subjected by calculating the coefficient of the inner consistency of the Cronbach alpha, and an estimate of the reliability of the variables was made by calculating the interstellar statistics.

\section{Results}

The proposed Screening model consisted of 28 evaluation variables with Likert type responses $(1-5)$. Since factor analysis begins with interrcorelation of manifest variables, the correlation coefficients have been calculated, with the aim of inspecting the matrix of the obtained coefficients greater than 0.30 . According to Tabachnik and Fidell (2007) [14], one of the conditions for subjective variables to undergo factor analysis is that their interconnectedness is greater than 0.30 . Of the 28 manifest variables, 16 of them had correlations greater than 0.30 , and they were taken for further consideration.

Prior to factorization, a set of 16 variables were subjected to the calculation of the coefficient of the internal consistency of the Cronbach alpha, and an estimate of the reliability of the variables was made by computing inter-item statistics. On the basis of the obtained results of Cronbach's alpha, which is 0.85 , it can be 
concluded that a set of 16 variables observed as a complete instrument have satisfactory reliability and internal agreement for the observed sample of the respondents. Table 1 shows the interstellar statistics and reliability within the instrument. The arithmetic meanings of the instrument range from 24.80 to 26.48; variance chart from 49.47 to 54.28 ; Cronbach $\alpha$ coefficient ranges from 0.84 to 0.86 . The mutual correlations of the variables with the instrument vary from 0.26 to 0.59 . According to the Pallant (2011) guidelines, if the degree of correlation of each variable with a total score is less than 0.30 , this result shows that the variable measures something different, not what measures the whole scale. In relation to this, a variable called "Do you have a disease of a more persistent character, variable weight (diabetes, epilepsy, asthma)" has a coefficient of less than 0.30 and has not been subjected to factorization, which ultimately only 15 variables enter the system manifest variables.

Table 1. Interpersonal statistics and reliability within the instrument.

\begin{tabular}{|c|c|c|c|c|}
\hline Variables & $\begin{array}{l}\text { The arithmetic } \\
\text { mean of the } \\
\text { scale if the } \\
\text { particle is } \\
\text { thrown out }\end{array}$ & $\begin{array}{l}\text { Variance of the } \\
\text { scale if the } \\
\text { particle is } \\
\text { thrown out }\end{array}$ & $\begin{array}{l}\text { Correlation of } \\
\text { particles- } \\
\text { belonging scale }\end{array}$ & $\begin{array}{l}\text { Cronbach } \alpha \\
\text { if the particle is } \\
\text { thrown out }\end{array}$ \\
\hline 1) Difficulties during lessons & 25.69 & 50.62 & 0.53 & 0.84 \\
\hline 2) Difficulties in learning & 25.43 & 49.56 & 0.59 & 0.84 \\
\hline 3) Difficulties in taking written or oral exams & 25.22 & 49.75 & 0.55 & 0.84 \\
\hline 4) Lack of time when writing an exam & 24.80 & 50.96 & 0.34 & 0.86 \\
\hline 5) Financial difficulties during the study & 25.29 & 50.46 & 0.40 & 0.85 \\
\hline $\begin{array}{l}\text { 6) Difficulties in reading (especially loud), difficulties in } \\
\text { understanding the read, problems in decoding new words, } \\
\text { terminology, quickly forgetting }\end{array}$ & 25.92 & 50.29 & 0.59 & 0.84 \\
\hline $\begin{array}{l}\text { 7) Difficulties in quick writing (capturing notes), difficulties } \\
\text { in organizing learning, handwriting problems (uncertainties, } \\
\text { illegibility) }\end{array}$ & 25.78 & 49.47 & 0.58 & 0.84 \\
\hline 8) Difficulties in making notes in lectures & 25.73 & 49.89 & 0.57 & 0.84 \\
\hline $\begin{array}{l}\text { 9) Difficulties with voice: inadequate height, quality, volume, } \\
\text { resonance or duration }\end{array}$ & 26.09 & 51.48 & 0.53 & 0.84 \\
\hline $\begin{array}{l}\text { 10) Speech difficulties (omission or replacement of voices), } \\
\text { stuttering, hastiness }\end{array}$ & 26.23 & 52.71 & 0.48 & 0.84 \\
\hline $\begin{array}{l}\text { 11) Expressive Difficulties (difficulty expressing, poor } \\
\text { vocabulary, agrammatic sentence) }\end{array}$ & 26.17 & 52.01 & 0.56 & 0.84 \\
\hline $\begin{array}{l}\text { 12) Receptive difficulties (misunderstanding of verbal tasks, } \\
\text { difficulties in understanding written text }\end{array}$ & 26.23 & 52.59 & 0.56 & 0.84 \\
\hline $\begin{array}{l}\text { 13) Disease of a lasting character, variable weight (diabetes, } \\
\text { epilepsy, asthma ...) }\end{array}$ & 26.48 & 55.96 & 0.26 & 0.85 \\
\hline 14) Difficulties in building interpersonal relationships & 26.30 & 54.28 & 0.40 & 0.85 \\
\hline $\begin{array}{l}\text { 15) Inappropriate type of behavior, mood swings, unhappiness, } \\
\text { depression, fear, hyperactive disorder, tics }\end{array}$ & 26.14 & 52.58 & 0.43 & 0.85 \\
\hline 16) Difficulties of movement and access to objects & 26.40 & 55.10 & 0.36 & 0.85 \\
\hline
\end{tabular}


An insight into the obtained matrix of intercorrelation of manifest variables determined the correlation of 0.30 and more on 15 evaluation variables that were ultimately taken for further analysis.

In order to reduce manifold variables to latent dimensions, a multivariate method of explorative factor analysis was used to determine factors in an area when the number and structure of the factors are not known in advance. Factors are considered to be the cause of covariance of manifest variables which give an explanation for the connection of phenomena that are examined by manifest variables. Since factor analysis begins with intercorrelation, the insight into the obtained results can lead to the conclusion of the 15 variables of the estimation taken in the analysis.

After insight into the intercorrelation of manifest variables, Kayser Mayer Olkin and Bartlets test was made, which represents a measure of the representativity of the pattern of a set of manifest variables, thus obtaining the ratio of real and quadrangular correlations and quadrangular partial correlations. It was established on the basis of the obtained coefficients of 0.89 with the reliability h2 = 25102.69 that there is justification of the set of variables to undergo factor analysis. The main components of Harold Hoteling were used in the method, according to which the number of main components is obtained as the number of initial variables. The main components are calculated in succession foremost the first, then the second, etc., where the first major component counts on the complete matrix of intercorelation variables and explains the largest amount of variance of the variable. Direct rotation was selected from rotations. Of the criteria, Guttman Kaiser's criterion is chosen, which implies that those factors or components with a characteristic value above one are left.

In Table 2, it can be noticed that the system of 15 manifest variables is reduced to 3 main components, and it is visible that the first major component explains the largest amount of variance of the variables and it is $34.81 \%$ of the variability. When the first major component is calculated, a second major component having a lower coefficient than the first one is accounted for, since a part of the common variance of the variables is used to form the first major component. The second major component is $12.06 \%$ and the third is $7.78 \%$.

Table 3 shows the projections of the variables on the first isolated component, and it can be noticed that the largest projections on the isolated factor achieved 7 variables with high parallel and orthogonal projections. The following variables

Table 2. Proprietary values (lambda), cumulative variance (percentage matrix intercorrelation of variables, percentage of common variance.

\begin{tabular}{cccc}
\hline Factor & Proprietary values & Percentage of variance & Cumulative variance \\
\hline 1 & 5.22 & 34.81 & 34.81 \\
2 & 1.81 & 12.06 & 46.88 \\
3 & 1.16 & 7.78 & 54.67 \\
\hline
\end{tabular}


have made the greatest parallel and orthogonal projections "Do you have difficulty speaking (omission or replacement of voices), stuttering, rush", "Do you have expressive difficulties (difficulty expressing, poor vocabulary, agramatic sentence)", "Do you have difficulty with voice: inadequate height, quality, volume, resonance or duration", "Do you have receptive difficulties" (misunderstanding of verbal orders, difficulties in understanding written texts). By inspecting an isolated structure, this factor can be called the Communication Factor.

Table 4 shows the projections of the variables to another isolated component. The largest projections for the isolated factor were achieved by 5 variables. The following variables have the biggest parallel and orthogonal projections "Do you have some difficulty in taking a written or oral exam", "Do you have some learning difficulties" and "Do you have any difficulty in following the lesson". By inspecting the isolated structure, this factor can be called the Learning Factor.

Table 5 shows the projections of the variable to the third isolated component.

Table 3. Isolated first major component.

\begin{tabular}{llc}
\hline \multicolumn{1}{c}{ Variables } & PAP & ORP \\
\hline Speech Difficulties (omitting or replacing voices), stuttering, rushing & 0.799 & 0.753 \\
Expressive difficulties (heavy speech, poor vocabulary, agrammatic recess) & 0.750 & 0.781 \\
Difficulties with voice: inappropriate height, quality, volume, resonance or duration & 0.730 & 0.703 \\
Receptive difficulties (unclear verbal orders, the essence of understanding the written text & 0.589 & 0.752 \\
$\begin{array}{l}\text { Difficulties in writing (capturing notes), difficulties in organizing learning, problems associated with } \\
\text { manuscripts (dyslexia, inaccessibility) }\end{array}$ & 0.575 \\
$\begin{array}{l}\text { Difficulties in reading (especially loud), difficulties in understanding read, problems in decoding new } \\
\text { words, terminology, quickly forgetting }\end{array}$ & 0.470 \\
Difficulties in making notes in lectures & 0.671 \\
\hline
\end{tabular}

Table 4. Isolated second component.

\begin{tabular}{|c|c|c|}
\hline Variables & PAP & ORP \\
\hline Difficulties in taking written or oral exams & 0.793 & 0.791 \\
\hline Difficulties during learning & 0.749 & 0.785 \\
\hline Difficulties during lessons & 0.737 & 0.746 \\
\hline Lack of time when writing an exam & 0.641 & 0.614 \\
\hline Financial difficulties during the study & 0.508 & 0.536 \\
\hline
\end{tabular}

Table 5. Isolated third component.

\begin{tabular}{lcc}
\hline \multicolumn{1}{c}{ Variables } & PAP & ORP \\
\hline Inappropriate type of behavior, mood swings, unhappiness, depression, fear, hyperactive disorder, tics & 0.758 & 0.783 \\
Difficulties in building interpersonal relationships & 0.745 & 0.772 \\
Difficulties of movement and access to objects & 0.703 & 0.728 \\
\hline
\end{tabular}


The largest projections for the isolated factor were achieved by 3 variables. All three variables have achieved high parallel and orthogonal projections and insight into the obtained structure of variables, so this factor can be called the Factor of Behavior and Social Skills.

\section{Discussion}

Assessment of the reliability and internal conformity of the variants of the screening model Questionnaire for students in higher education and the insight into the obtained matrix of intercorrelations of manifest variables found that 15 variables of the assessment considered as a complete instrument have satisfactory reliability and internal agreement and can be used as a recommended screening model. Zygouris and associates (2015) [15] state that a screening instrument can only indicate whether a student needs to be referred to a special needs coordinator, does not mean that the student will be diagnosed with a certain difficulty. The primary aim of the screening validation is to first consider whether a student needs a psycho-education evaluation, and to identify the student, where the ultimate goal is to improve the effectiveness of the support service [16]. In this research, our intention was to develop and validate a screening model for identifying and referring to a further process for support in higher education institutions, whereby the model aims to identify students requiring further careful analysis or assessment. Quality assessments are costly, difficult to attain, and may be perceived as negative and intrusive by some students [2], so with this model we want to prevent the negative experience of most students, and reduce the costs that the assessment itself requires.

In any case, the results of this research offer a screening model for discovering students with hidden difficulties, which can serve not only in the higher education system in Bosnia and Herzegovina, but also in other countries where objectively still the system of diagnostics and support does not exist at lower levels of education or developed in higher education. It is precisely the validation of the screening model itself that enables higher education institutions in Bosnia and Herzegovina, not only public but also private, their timely detection and creation of support systems, as well as curricular reforms aimed at universal design, equal opportunities and more efficient pedagogical practices, which will enable better conditions for academic success.

\section{Conclusions}

By using the multivariate method of exploratory factor analysis, a system of 15 manifest variables/scans of the instrument is reduced to 3 main components, which are defined as a communication factor, a learning factor and a behavior factor and social skills. Just reading, writing, listening carefully, managing skills, expressive skills and communication skills in relationship are the most important communication skills for students. The 21 st century learning skills are often called the 4 C's: critical thinking, creative thinking, communicating, and colla- 
borating. These skills help students learn, and so they are vital to success in school and beyond [17].

The administration of screening model is fast and does not require special preparation of respondents. The validation of the screening model for further referrals for diagnostics indicated that the model is also appropriate in the quality control system and services provided by higher education institutions that are in line with the European Quality Control Guidelines for Higher Education. It can be incorporated into existing guides to ensure equal opportunities in higher education and become a standard in procedures for early detection of risky students. Findings support the requirement for a reliable and valid standardized assessment procedure for HEIs, which would provide an equitable access to initial diagnosis and ensure further support.

\section{Funding}

This research was funded by international Tempus project "Equal opportunities for students with special needs in higher education". The Project was funded by EACEA. The content of this publication does not necessarily reflect the views or policies of EACEA. The authors had nonfinancial or other conflicts of interest.

\section{References}

[1] Raue, K., Lewis, L. and Coopersmith, J. (2011) Students with Disabilities at Degree-Granting Postsecondary Institutions: A First Look. U.S. Department of Education, Washington DC.

[2] Couzens, D., Poed, S., Kataoka, M., Brandon, A., Hartley, J. and Keen, D. (2015) Support for Students with Hidden Disabilities in Universities: A Case Study. International Journal of Disability, Development and Education, 62, 24-41. https://doi.org/10.1080/1034912X.2014.984592

[3] May, A.L. and Stone, C.A. (2010) Stereotypes of Individuals with Learning Disabilities: Views of College Students with and without Learning Disabilities. Journal of Learning Disabilities, 43, 483-499. https://doi.org/10.1177/0022219409355483

[4] Tops, W., Callens, M., Lammertyn, J., Van Hees, V. and Brysbaert, M. (2012) Identifying Students with Dyslexia in Higher Education. Annals of Dyslexia, 62, 186-203. https://doi.org/10.1007/s11881-012-0072-6

[5] Lancaster, S. and Mellard, D. (2005) Adult Learning Disabilities Screening Using an Internet-Administered Instrument. Learning Disabilities-A Contemporary Journal, 3, 62-73.

[6] Klassen, R., Krawchuk, S., Lynch, L. and Rajani, S. (2008) Procrastination and Motivation of Undergraduates with Learning Disabilities: A Mixed-Methods Inquiry. Learning Disabilities Research \& Practice, 23, 137-147. https://doi.org/10.1111/j.1540-5826.2008.00271.x

[7] Al-Yagon, M. and Margalit, M. (2013) Social Cognition of Children and Adolescents with LD: Intrapersonal and Interpersonal Perspectives. In: Harris, K., Graham, S. and Swanson, L., Eds., Handbook of Learning Disabilities, Guilford Press, New York, 278-292.

[8] Idan, O. and Margalit, M. (2013) Hope Theory in Education Systems. In: Katsaros, G.M., Ed., Psychology of Hope, Nova, New York, 139-160. 
[9] Hale, J.B., Alfonso, V.C., Berninger, V.W., Bracken, B., Christo, C., Clark, E. and Yalof, J. (2010) Critical Issues in Response-to-Intervention, Comprehensive Evaluation and Specific Learning Disabilities Identification and Intervention: An Expert White Paper Consensus. Learning Disability Quarterly, 33, 223-236. https://doi.org/10.1177/073194871003300310

[10] Bratovčić, V., Junuzović-Žunić, L., Dizdarević, A. and Teskeredžić, A. (2013) Students with Physical Disabilities in Higher Education. Sarajevo, World University Service of Bosnia and Herzegovina (SUSBiH). (The Book Was Created within the Tempus Project "Equal Opportunities for Students with Special Needs in Higher Education (EQOPP) (2011-2014)".

[11] Dizdarević, A. and Bijedić, M. (2013) University Guide for Students with Special Needs. World University Service of Bosnia and Herzegovina, Sarajevo.

[12] Lovett, B.J., Nelson, J.M. and Lindstrom, W. (2014) Documenting Hidden Disabilities in Higher Education: Analysis of Recent Guidance from the Association on Higher Education and Disability. Journal of Disability Policy Studies, 26, 44-53.

[13] Duranović, M. and Mrkonjić, Z. (2013) Estimation of Dyslexia. Printcom doo, Tuzla.

[14] Tabachnik, B.G. and Fidell, I.S. (2007) Using Multivariate Statistics. 5th Edition, Pearson Education, Boston.

[15] Zygouris, N.C., Vlachos, F., Dadaliaris, A.N., Stamoulis, G.I., Vavougios, D., Nerantzaki, E. and Striftou, A. (2015) Learning Difficulties Screening Web Application. Proceedings of 2015 International Conference on Interactive Collaborative Learning, Florence, 20-24 September 2015, 20-24. https://doi.org/10.1109/ICL.2015.7318103

[16] VanDerHeyden, A.M., Witt, J.C. and Naquin, G. (2003) The Development and Validation of a Process for Screening and Referrals to Special Education. School Psychology Review, 32, 204-227.

[17] AMA (2010) Critical Skills Survey: Executive Summary. American Management Association.

http://www.p21.org/storage/documents/Critical\%20Skills\%20Survey\%20Executive \%20Summary.pdf 